\title{
REDOR NMR Distance Measurements for the Tubulin-Bound Paclitaxel Conformation
}

\author{
Younkee Paik $^{\perp}$, Chao Yang ${ }^{\dagger}$, Belhu Metaferia ${ }^{\dagger}$, Shoubin Tang ${ }^{\dagger}$, Susan Bane ${ }^{\ddagger}$, Rudravajhala \\ Ravindra $\ddagger$, Natasha Shanker ${ }^{\ddagger}$, Ana A Alcaraz $\S$, Scott A. Johnson $\S$, Jacob Schaefer ${ }^{\perp}$, Robert \\ D. O'Connor ${ }^{\perp}$, Lynette Cegelski ${ }^{\perp}$, James P. Snyder $§$, and David G. I. Kingston ${ }^{\dagger}$ \\ Department of Chemistry, M/C 0212, Virginia Polytechnic Institute and State University, Blacksburg, \\ VA 24061, Department of Chemistry, State University of New York at Binghamton, Binghamton, NY \\ 13902, Department of Chemistry, Emory University, Atlanta, GA 30322, and Department of \\ Chemistry, Washington University, St. Louis, MO 63130
}

\begin{abstract}
The important anticancer drug Taxol ${ }^{\circledR}$ (paclitaxel, PTX) owes its unique activity to its ability to bind to tubulin in a stoichiometric ratio and promote its assembly into microtubules. The conformation of the microtubule-bound drug has been the focus of numerous research efforts, since the inability of polymerized tubulin to form crystals precludes structure proof by X-ray crystallography. Likewise, although the $\alpha \beta$-tubulin dimer structure has been solved by electron crystallography, the $3.7 \AA$ resolution is too low to permit direct determination of either ligand conformation or binding pose. In this study we present experimental results from ${ }^{2} \mathrm{H}\left\{{ }^{19} \mathrm{~F}\right\}$ REDOR NMR that provide direct confirmation that paclitaxel adopts a T-shaped conformation when it is bound to tubulin.
\end{abstract}

\section{Introduction}

The natural product paclitaxel (PTX) $\left(\right.$ Taxol $\left.^{\circledR}, \mathbf{1}\right)$ is a major cancer chemotherapeutic agent which is in clinical use for the treatment of breast, lung, and ovarian carcinomas. ${ }^{1}$ Its importance is underscored by the fact that a number of analogs with improved activities have been prepared, some of which are in clinical trials. ${ }^{2}$ PTX acts as a microtubule stabilizer, binding to microtubules and blocking microtubule dynamics, ultimately leading to damage to the mitotic spindle and apoptosis. ${ }^{3}$ Although PTX has other biological effects, its clinical activity is believed to be directly related to its microtubule-binding activity. $3 \mathrm{e}, 4$

\footnotetext{
E-mail:dkingston@vt.edu.

Tirginia Polytechnic Institute and State University

${ }_{\text {State University of New York at Binghamton }}$

\$Emory University

$\perp_{\text {Washington University }}$
}

Supporting Information Available: Full experimental details of the syntheses of labeled PTX analogs $4-\mathbf{5}$ and S23. Figure S1: Pulse sequence for ${ }^{2} \mathrm{H}\left\{{ }^{19} \mathrm{~F}\right\}$ REDOR. Figure $\mathrm{S} 2\left({ }^{2} \mathrm{H}\left\{{ }^{19} \mathrm{~F}\right\}\right.$ REDOR spectra of $\mathrm{D}-\left[2-{ }^{2} \mathrm{H}, 3-{ }^{19} \mathrm{~F}\right]$ alanine dispersed in a solid buffer as a function of the dipolar evolution time). Figure $\mathrm{S} 3\left({ }^{2} \mathrm{H}\left\{{ }^{19} \mathrm{~F}\right\}\right.$ REDOR spectra of tubulin-bound paclitaxel analog 5 and ${ }^{2} \mathrm{H}\left\{{ }^{19} \mathrm{~F}\right\}$ REDOR spectra of a control sample of D-[3- $\left.{ }^{2} \mathrm{H} 3\right]$ alanine). Figure $\mathrm{S} 4$ (Cross-polarization magic-angle spinning ${ }^{19} \mathrm{~F}$ and ${ }^{2} \mathrm{H}$ NMR spectra of tubulinbound paclitaxel analog 4, and simulated spectra using SIMPSON). Complete Ref. 24. 


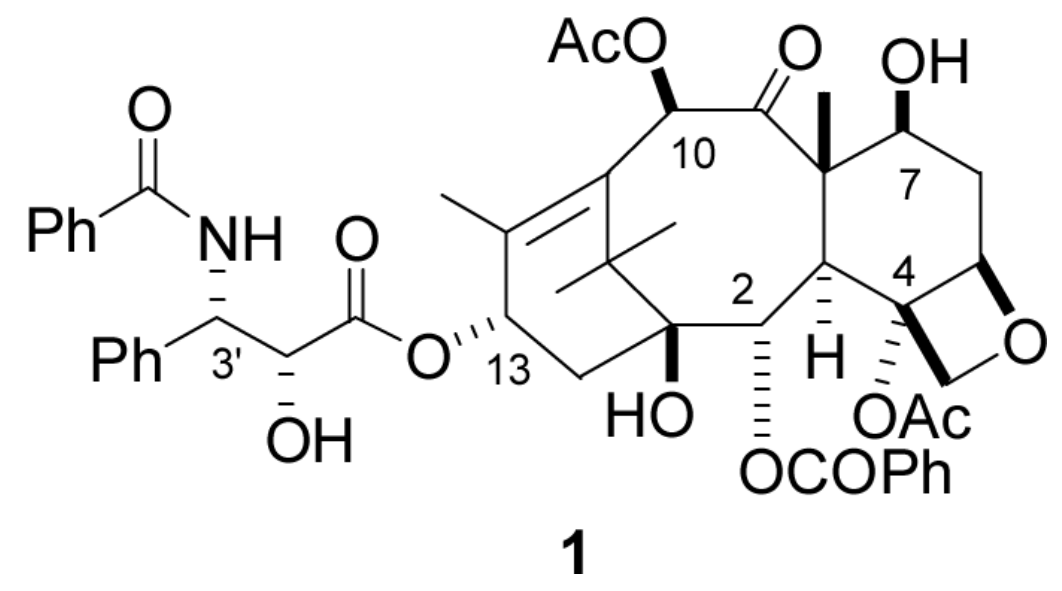

One aspect of the binding of PTX to microtubules that is still being subjected to test is the conformation of the various side chains in the bound molecule. Although PTX has a relatively rigid tetracyclic ring system, it has four flexible side chains at $\mathrm{C} 2, \mathrm{C} 4, \mathrm{C} 10$, and $\mathrm{C} 13$, and the presence of these freely rotatable units gives rise to numerous possible conformations. A detailed understanding of the microtubule-binding conformation of PTX could in principle lead to the development of improved and perhaps greatly simplified analogs. The elucidation of this conformation is thus a matter of potential practical as well as theoretical significance.

The direct approach of determining the binding conformation of the microtubule-PTX complex by X-ray crystallography is not available because of the polymeric and non-crystalline nature of the complex. Although it has proved possible to determine the structure of the tubulin dimer at $3.7 \AA$ by electron crystallography of PTX-stabilized zinc-induced tubulin sheets, ${ }^{5}$ the structure lacks the resolution to define the detailed conformation of PTX on the tubulin polymer. It is thus necessary to use indirect methods to determine the bound conformation of PTX. Standard solution state NMR methods cannot be used for microtubule-bound PTX due to the aqueous insolubility of the polymeric receptor. Nonetheless, recent advances in NMR spectroscopy carry the promise of exploiting spin-diffusion to determine relative binding modes of microtubule-promoting ligands, including baccatin III, competing for the same binding site. ${ }^{6}$ In an alternative approach, solution state NMR analysis of PTX conformations in the absence of the protein coupled with molecular dynamics simulations and the electron crystallographic density of the tubulin-PTX complex led to the proposal of T-Taxol as the bound conformation. ${ }^{7}$

Most previous studies of the bioactive conformation have used evidence from solution NMR analyses and molecular modeling, and have led to the proposal of three different models for the solution conformation of PTX. NMR studies in nonpolar solvents suggested a "nonpolar" conformation with hydrophobic interactions between the $\mathrm{C} 2$ benzoate and the $\mathrm{C} 3$ '-benzamido group. ${ }^{8}$ A "polar" or hydrophobic collapsed conformation was then proposed on the basis of NMR studies in polar solvents; this conformation features hydrophobic interactions between the $\mathrm{C} 2$ benzoate, the $\mathrm{C} 3$ ' phenyl group, and the $\mathrm{C} 4$ acetate. ${ }^{9-12}$ More recent studies using the NAMFIS deconvolution approach have shown that PTX adopts 9-10 conformations in $\mathrm{CDCl}_{3}, 13$ none of which achieves a population above $30 \%$.

Although studies of the solution-phase conformations of PTX have been instructive, they cannot furnish direct information on the microtubule-bound conformation. The determination of the latter requires direct observation of microtubule-bound PTX, which necessitates the use of a technique that will permit measurement of internuclear distances on the ligand of a PTXmicrotubule complex. Fortunately, rotational-echo double resonance (REDOR) ${ }^{14}$ allows just 
this measurement. One study using this technique has appeared to date. This study used the 2( $p$-fluorobenzoyl)PTX 2 with ${ }^{13} \mathrm{C}$ labels at the $\mathrm{C} 3$ ' amide carbonyl and $\mathrm{C} 3$ ' methine carbons, and yielded $\mathrm{F}_{-}{ }^{13} \mathrm{C}$ distances of 9.8 and $10.3 \AA$ between the fluorine and the $\mathrm{C} 3$ ' amide carbonyl and C3' methine carbons, respectively. ${ }^{15,16}$

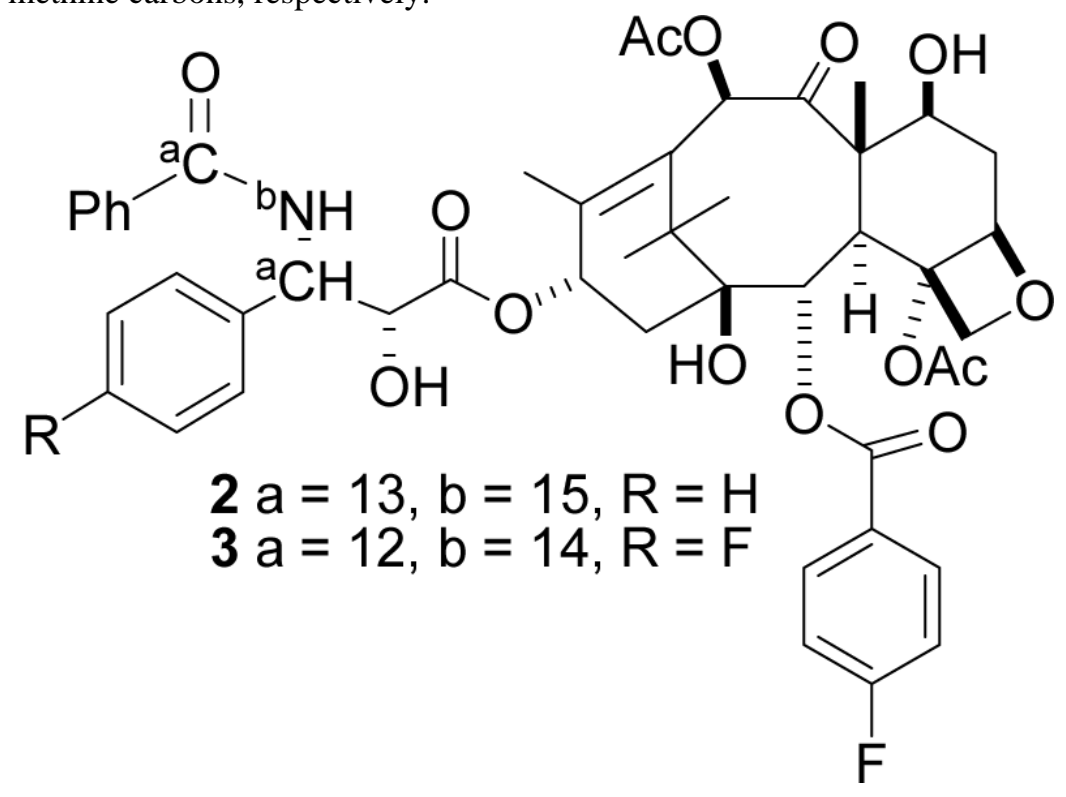

Analysis of the existing NMR data, both solution phase and REDOR, in conjunction with knowledge of the electron crystallographic density of $\beta$-tubulin, led to the postulation of the T-Taxol conformation as the microtubule-binding conformation. ${ }^{7,17}$ Subsequently, a slightly different structure consistent with the REDOR data was proposed as the bioactive tubulinbinding conformation of PTX. ${ }^{18}$ However, the same structure is inconsistent with the electron crystallographic density for PTX at the tubulin-taxane binding site. ${ }^{17,19}$ The T-Taxol conformation has been strongly supported by indirect evidence showing that the synthesis of constrained analogs based on this conformation yields compounds with improved activity. 20 In this paper, we provide data on the synthesis and REDOR NMR analysis of additional PTX analogs which provide further experimental evidence for the T-Taxol conformation.

\section{Results and Discussion}

\section{Design and synthesis of PTX analogs for REDOR analysis}

An analysis of the proposed bioactive T-Taxol conformation (Figure 1) 7,17 indicated that the C3' phenyl group on the side chain was positioned quite close to the methyl group of the $\mathrm{C} 4$ acetate unit. This observation, in fact, was the inspiration for the synthesis of highly active bridged taxanes matching and, in some cases, surpassing the activity of parent PTX. ${ }^{20} \mathrm{~A}$ critical test of the T-Taxol conformation would be determination of the distance between these two groups at the tubulin-taxane binding site. Unfortunately, the previous REDOR studies, with PTX analogs 2 and 3 labeled on the C2 benzoate and on the C13 side chain, ${ }^{15}$ provided no information on the spatial separation of the $\mathrm{C} 4$ acetate methyl group and atoms or groups located in other side chains.

These considerations led to the design of the two PTX analogs $\mathbf{4}-\mathbf{5}$ as ligands to determine key distances in microtubule-bound PTX. Ligand $\mathbf{4}$ was particularly attractive, since in principle it allows the determination of two key distances; namely, between the $\mathrm{C} 4$ acetate and the $\mathrm{C} 2$ benzoate and between the $\mathrm{C} 2$ benzoate and the $\mathrm{C} 3$ ' phenyl. In the event, only a lower 
boundary on the latter distance could be determined for technical reasons, as discussed below. Ligand $\mathbf{5}$ was designed to allow a direct measurement of the distance between the $\mathrm{C} 4$ acetate and the $\mathrm{C} 3$ ' phenyl.
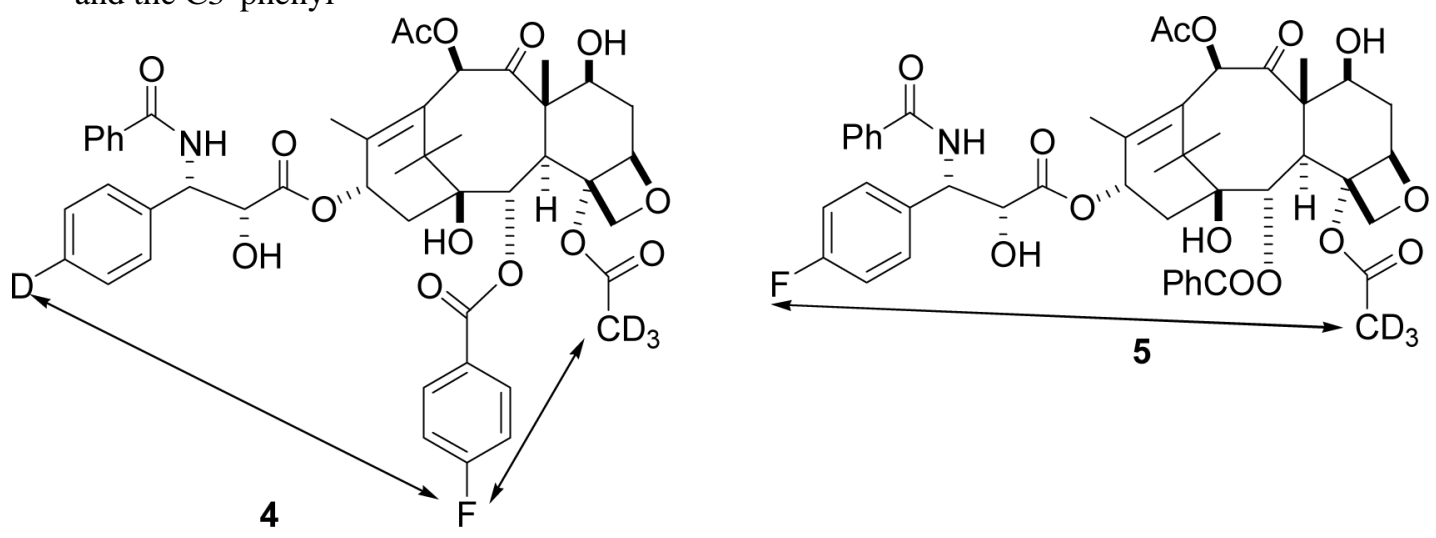

The labeled PTX derivatives were prepared from the available 10-deacetylbaccatin III. The retrosynthetic analysis of $\mathbf{4}$ is shown in Scheme 1 below.

The forward synthesis sequence is shown in Scheme 2. 10-deacetylbaccatin III was converted to the $\mathrm{C} 2$ debenzoylated compound $\mathbf{6}$ by the literature procedure, ${ }^{21}$ which was rebenzoylated to give 4-fluorobenzoate 7 in $75 \%$ yield. Deacetylation of the 4-acetate group by the published procedure $^{22}$ gave the $\mathrm{C} 4$ alcohol $\mathbf{8}$, and this was reacetylated with deuterated acetyl chloride to give the acetate 9 in $66 \%$ yield. The low yield from the acetylation reaction is attributed to partial loss of the dimethylsilyl protecting group and to incomplete conversion of the starting material, even after a prolonged reaction period $(72 \mathrm{hrs})$. Global deprotection was followed by selective acetylation ${ }^{23}$ of the $10-\mathrm{OH}$ mediated by $\mathrm{CeCl}_{3}$ to give compound $\mathbf{1 0}$. Selective reprotection of the 7-OH group completed the synthesis of the labeled baccatin core $\mathbf{1 1}$.

The syntheses of the required $\beta$-lactam derivative was achieved by literature procedures (Scheme 3) ${ }^{24}$ The selected starting material was 2-bromo benzaldehyde (12), which was converted to the deuterated acetal 13 and thence to the deuterated $\beta$-lactam 14 through the $N$ ( $p$-methoxy phenyl) (PMP) protected imines. Resolution of the ( \pm )- $\beta$-lactam 14 was carried out with lipase PS (Amano) to yield the acetate of the desired (+)-enantiomer (15), along with the (-)-alcohols (not shown) in more than $95 \%$ combined yield. Functional group manipulations on 15 generated the triisopropylsilyl ether intermediate 16, which was benzoylated to give the deuterated $(+)-(3 R, 4 S)$-1-benzoyl-3-triisopropylsilyloxy-4-( $p$-deuterophenyl)azetidin-2-one 17.

The final steps of the synthesis of the target taxol analog (4) consisted of a coupling reaction between the baccatin core (11) and $\beta$-lactam (17) followed by deprotection (Scheme 4 ).

Compound 5 was prepared by a similar route; the final steps are shown in Scheme 5, and full details of all synthetic procedures are included as Supporting Data.

\section{Biological evaluation of REDOR analogs}

The key activity criterion for the REDOR studies was the ability of the two compounds to promote tubulin assembly. In this respect both analogs proved to be effective agents; compound $\mathbf{4}$ was about twofold less active than paclitaxel while compound $\mathbf{5}$ was almost as active as paclitaxel (Table 1). Both compounds were also evaluated for cytotoxicity towards the A2780 ovarian cancer line. In this assay the differences were more marked. The analog $\mathbf{4}$ was more than two orders of magnitude less cytotoxic than paclitaxel against the A2780 ovarian cancer 
cell line, consistent with data on other similarly substituted analogs, ${ }^{25}>$ while analog $\mathbf{5}$ was comparable in cytotoxicity to paclitaxel. ${ }^{26}$

\section{REDOR Spectra and ${ }^{2} \mathrm{H}-{ }^{19} \mathrm{~F}$ Distances}

A symmetrical, full quadrupolar spectrum (broken up into spinning sidebands) is observed for the D- $\left[2-{ }^{2} \mathrm{H}, 3-{ }^{19} \mathrm{~F}\right]$ alanine reference compound (Figure 2, bottom). This result indicates distortion-free ${ }^{2} \mathrm{H}$ detection over a bandwidth of more than $150 \mathrm{kHz}$. Although strong $\mathrm{n}= \pm 8$ spinning sidebands are observed for the alanine reference, they are weak in the spectrum of tubulin-bound 4 (Figure 2, top); the strong central part of the spectrum of tubulin-bound $\mathbf{4}$ is due to its $\mathrm{CD}_{3}$ group. We attribute this result to small-amplitude, low-frequency motions within the microtubule complex that interfere with echo formation for an aromatic ${ }^{2} \mathrm{H}$ with a large quadrupolar interaction. We believe that the motion is small amplitude because the CPMAS ${ }^{19} \mathrm{~F}$ spectrum of tubulin-bound $\mathbf{5}$ is full strength, and the ${ }^{19} \mathrm{~F}$ of $\mathbf{5}$ is on the same ring as the ${ }^{2} \mathrm{H}$ of 4. Such motions are not present in the rigid lattice of the alanine crystal. The $8 \%$ dephasing of the methyl- ${ }^{2} \mathrm{H}$ peak (Figure 3) translates into an $\mathrm{R}^{1}-\mathrm{R}^{2}$ distance of $7.8 \pm 0.5 \AA$ (Table 2). The $\mathrm{R}^{1}-\mathrm{R}^{3}$ distance in tubulin-bound $\mathbf{5}$ is $6.3 \pm 0.5 \AA$ (Figure 4, inset, and Table 2).

The final key distance is the distance between $\mathrm{R}^{2}$ and $\mathrm{R}^{3}$ in tubulin-bound 4 . We expected an intensity ratio of methyl to aromatic ${ }^{2} \mathrm{H}$ peaks of 3 to 1 for tubulin-bound $\mathbf{4}$, but instead observed a ratio of about 14:1 (Figure 3). This made quantitative determination of the dephasing of the aromatic ${ }^{2} \mathrm{H}$ peak difficult and impractical for longer evolution times and even weaker signals. Nevertheless, we are confident that the $100 \%$ dephasing predicted by the polar model (Table 2) for an $R^{2}-R^{3}$ distance of $4.6 \AA$ is not present. The maximum possible dephasing is less than $10 \%$, and is very likely much less than $10 \%$. We conclude that the $\mathrm{R}^{2}-\mathrm{R}^{3}$ distance is greater than $8 \AA$.

\section{REDOR Quantitation}

Our conclusions about ${ }^{2} \mathrm{H}_{-}{ }^{19} \mathrm{~F}$ distances from REDOR experiments depend on the efficiency of the REDOR dephasing pulses. We tested this efficiency using the alanine reference compound of Figure 2. The observed dephasing was close to $100 \%$ after $4 \mathrm{msec}$ (Figure 4 ) and consistent with a 3-bond distance in alanine.

The distance determinations also depend on the stability of the spectrometer under the longterm time averaging required to measure small differences between weak signals. For example, to determine the $\mathrm{R}^{1}-\mathrm{R}^{3}$ distance in just $0.1 \mu$ moles of tubulin-bound $\mathbf{5}$ required more than 1 million scans and 3 weeks of spectrometer time. The stability of the spectrometer for such an extended period was confirmed by performing an identical ${ }^{2} \mathrm{H}\left\{{ }^{19} \mathrm{~F}\right\}$ experiment on a deuterated alanine sample that had no ${ }^{19} \mathrm{~F}$ label. No REDOR difference was observed (Figure S3 of the Supplementary Material). Short-term spectrometer stability in REDOR experiments is guaranteed by scan-to-scan alteration of the collection of dephased-echo (S) and full-echo $\left(\mathrm{S}_{0}\right)$ signals. Long-term stability arises from active control of the temperature-dependent drift in the power amplifiers. ${ }^{27}$ This control eliminates fluctuations in pulse amplitudes that result in spectral artifacts. The drive voltages for the power amplifiers were determined by a control circuit that compares the amplitudes of calibration pulses that follow both $\mathrm{S}$ and $\mathrm{S}_{0}$ acquisitions to a reference voltage. With this device, the power amplifiers were re-calibrated once a second throughout the entire 3-week data collection period.

The complete cancellation of $\mathrm{S}$ and $\mathrm{S}_{0}$ illustrated in Figure $\mathrm{S} 3$ (bottom) was also aided by the properties of the transmission-line probe that was used for the measurements. The ${ }^{19} \mathrm{~F}$ radiofrequency $(470.9 \mathrm{MHz})$ was introduced to the transmission line at an impedence miminum for the ${ }^{1} \mathrm{H}$ radiofrequency $(500.5 \mathrm{MHz})$. This provided about a $40 \mathrm{~dB}$ isolation between the tune-and-match circuits for the two frequencies, ${ }^{28}$ and a total isolation (including filters and 
traps) of almost $90 \mathrm{~dB}$. There is no accidental leakage from one radiofrequency channel to another in transmission-line probes of this design.

\section{PTX Conformation Metrics; the Tubulin Bound Conformer}

As mentioned above, three contenders for the bioactive bound form of PTX have received high level attention over the past decade: the nonpolar conformer, the polar form and T-Taxol. The present solid-state REDOR-determined interatomic distances for labeled $\mathbf{4}$ and $\mathbf{5}$, combined with complementary structural information, permit a distinction among these spatially distinct forms. The polar model proposed as the binding conformation in several reports $8,9,10,15$ is entirely consistent with the solid state separations of $R^{1}-R^{2}$ and $R^{1}-R^{3}$ recorded in Table 2 . For all the PTX conformations discussed here, the constancy of $\mathrm{R}^{1}-\mathrm{R}^{2}$ is not surprising. The $\mathrm{C} 4$ acetate incorporating $\mathrm{R}^{1}$ methyl can adopt three conformations. However, only that with the $\mathrm{C}=\mathrm{O}$ moiety positioned under the 6-membered $\mathrm{C}$-ring is observed in single crystal $\mathrm{X}$-ray structures. The same conformation is predicted by various computational methods to be lowest in energy. Similarly, while the $\mathrm{C} 2-\mathrm{O}$ bond of the $\mathrm{C} 2$ benzoyl group can theoretically adopt two conformations, only one is observed either experimentally (i.e. X-ray structures) or computationally. The second tucks the carbonyl group into the concave cavity of the baccatin core causing severe steric compression. Consequently, adoption of the same conformations at $\mathrm{C} 2$ and $\mathrm{C} 4$ across the PTX conformational surface ensures a fixed $\mathrm{R}^{1}-\mathrm{R}^{2}$ as observed for the nonpolar, polar and T-Taxol rotamers (Table 2). On the other hand, $\mathrm{R}^{1}-\mathrm{R}^{3}$ can be expected to vary since the $\mathrm{C} 13$ side chain can assume a variety of conformations. ${ }^{17}$ The polar and nonpolar models present distances that are -0.8 and $+0.9 \AA$, respectively, from the REDOR value (Table 2 ). While these variations do not disqualify these conformers, they do highlight the fact that $\mathrm{T}$-Taxol is within $0.3 \AA$ of the $\mathrm{R}^{1}-\mathrm{R}^{3}$ measurement.

The $\mathrm{R}^{2}-\mathrm{R}^{3}$ phenyl-phenyl separation is crucial for rejecting the polar conformation as the bioactive form. The $4.5 \AA$ gap falls far short of the $>8 \AA$ measure required by the REDOR experiment. By contrast, T-Taxol and the nonpolar conformers are compatible with this datapoint. In fact both conformations would seem to match the trio of REDOR distances obtained in the present study reasonably well, an observation that might seem to confirm solution phase NMR-based speculations that the nonpolar form is the bioactive one. ${ }^{7}$ The fundamental difference between them is the absence or presence, respectively, of hydrophobic collapse between the C2 and C3' N-benzoyl phenyl groups. As indicated by the structure associated with Table 2, the latter are unlabeled. As a consequence, potential REDOR dephasing experiments that might provide information on the association of the two $\mathrm{C} 2$ and C3' phenyl rings at the binding site (or the lack of it) are silent. On the other hand, our earlier REDOR study ${ }^{15}$ provides $\mathrm{R}^{2}-\mathrm{CH}$ and $\mathrm{R}^{2}-\mathrm{C}$ separations that offer a clear distinction. Since these distances have been discussed recently for other conformers, ${ }^{17}$ the focus here will be the nonpolar conformer. The latter structure's $\mathrm{F}^{2}{ }^{13} \mathrm{CH}$ and $\mathrm{F}^{2}{ }^{13} \mathrm{C}$ distances of 8.5 and $6.2 \AA$ fall 1.8 and 3.6 $\AA$, respectively, below the REDOR values (Table 2). The large discrepancy in distances is a consequence of the deep-seated repositioning of the $\mathrm{C} 3 \mathrm{\prime} \mathrm{Ph}$ and NHCOPh moieties from polar to nonpolar conformers. Furthermore, the results are in satisfying agreement with previously reported evidence suggesting that the $\mathrm{C} 2$ to $\mathrm{C} 3$ ' collapse is prevented by His 227 which serves as the centerpiece of a sandwich incorporating the ligand phenyl groups on either side. ${ }^{7,20,29}$ A particularly compelling corroboration is the synthesis of bridged compounds holding the two phenyl groups in a collapsed orientation. Such compounds are inactive in the microtubule assembly assay and are unable to inhibit PTX binding. ${ }^{30}$ Other more recent efforts to tether the PTX framework to a nonpolar architecture have likewise led to compounds with low or no activity. ${ }^{31}$ For these reasons, the nonpolar conformation would appear to be ruled out as a contender for the taxane bioactive conformation. 
Two other conformations closely related to T-Taxol deserve mention. The first, the electron crystallographically refined structure $1 \mathrm{JFF},{ }^{5}$ is a close mimic of T-Taxol. ${ }^{7,17}$ In its conformational details, however, it is not quite as close a fit as the latter to the REDOR distances. Internal distances differ by 1.0-1.7 ̊ (Table 2). Thus, while the pdb-deposited lowresolution structure captures the essence of the bound conformation, the modeled refinement (T-Taxol) ${ }^{7,32}$ provides the best fit to the solid-state measurements. The second conformer, PTX-NY, ${ }^{18}$ is discussed in more detail below.

\section{Analysis of the PTX-NY Conformation. 33}

The PTX-NY conformation is a variation of the T-form that differs in the conformation of the $\mathrm{C}-13$ side chain from $\mathrm{C} 1$ '-C3'. ${ }^{18}$ It matches all of the REDOR distances well (Table 2), and so it is important to consider its candidacy for the paclitaxel bioactive conformation in the $\beta$ tubulin taxane binding site. In previous papers, we ruled out PTX-NY as a candidate since our reconstruction of it strongly suggested that the conformer does not fit the electron crystallographic (EC) density. ${ }^{17,19}$ Since the publication of these papers, Professor Ojima has kindly provided the original coordinates. This has made it possible to compare our reconstruction with the original and to perform two additional comparisons with it.

\section{PTX-NY Reconstruction}

Paclitaxel is a remarkably complex molecular skeleton with four-fused rings (A-D), eleven stereogenic centers and four seemingly flexible side chains at C-2, C-4, C-10 and C-13. Nonetheless, the baccatin core (A-D rings) is rigid. The acetate at C-10 is non-essential for bioactivity. C-2 and C-4 can, in principle, adopt a number of conformations, but in practice each assumes only one in solution and in the solid state of several analogs. That leaves C-13 as the primary flexible element in the molecule. However, apart from rotating phenyl rings, the conformation of this side chain is fully described by the following four dihedral angles: C12-C13-O13-C1', C13-O13-C1'-O1', O13-C1'-C2'-O2' and O2'-C2'-C3'-N3. For PTX-NY the literature gives these angles as $-160,+5,+20$ and +175 (Ref. 18, Figure 5) Accordingly, the corresponding four torsions in the T-Taxol conformation ${ }^{7}$ were changed to these values with no further alteration of the molecular structure. Figure 5 pictures PTX-NY (green) overlayed on the 4-angle modified T-Taxol (rust) by a five-point atom-atom superposition (i.e. C-2, C-11, $\mathrm{C}-13, \mathrm{C}-15$ and $\left.\mathrm{C}-3^{\prime}\right)$. The terminal phenyl rings are offset somewhat, particularly at C-2, but the conformation of PTX-NY is faithfully reproduced from C-1' to C-3' as highlighted by the circled atoms in Figure 5. As a result, the previous comparisons of conformations ${ }^{17,19}$ would appear to be valid.

\section{C-2 para-Fluorophenyl Orientation}

All distances in Table 2 that involve $\mathrm{R}^{2}$ (4 of 5) involve measurement from a fluorine atom at the para position of the $\mathrm{C}-2$ benzoyl phenyl to other atoms in the taxane structure. Accurate atomic separations in a given structure require that the fluorine is correctly located relative to other atoms in the molecule. Given the spatial discrepancy of the C-2 phenyl rings in Figure 5 , we decided to examine which of the two structures is responsible and to try to understand the origin of the difference. As standards, we selected the X-ray structures of two landmark taxanes: Taxol ${ }^{34}$ (PTX, paclitaxel, magenta) and taxotere ${ }^{35}$ (DTX, docetaxel, orange). These were supplemented with para-F atoms and superposed by aligning the baccatin cores (i.e. atoms C-2, C-11, C-13 and C-15). T-Taxol (yellow) was treated similarly. Figure 6a shows that in all 3 cases, the $\mathrm{C}-2$ ester group and the pendant phenyl rings overlap well; the 3 fluorines clustering within the red sphere with a radius of $1.1 \AA$ A. The identical superposition of PTXNY is shown in Figure 6b. It would appear that while the remainder of the paclitaxel molecule is reasonably optimized, the C-2 side chain in PTX-NY is at odds with the experimental structures. The origin of the displacement is captured in Figure 7 and quantified in Table 3. 
While the T-Taxol geometry around C-2 is very similar to the experimental structures, PTXNY exhibits a distortion characterized by a flattening of the C-2 tetrahedral geometry and by an expansion of $\theta_{3}$, the $\mathrm{C} 2-\mathrm{O}-\mathrm{C}(=\mathrm{O})$ bond angle, to $131^{\circ}$. Both work together to displace the $\mathrm{C}-2$ side chain towards the concave face of the baccatin core as illustrated by Figures $5 \mathrm{~b}$ and $6 \mathrm{~b}$. The implication is that while the PTX-NY structure closely matches the REDOR distances of Table 2, it is possible that the match for four of the five distances dependent on the location of the C-2 aromatic-F is fortuitous and based on a geometry that deviates significantly from experiment.

\section{Electron Crystallographic Density Fitting}

Our attempts to fit PTX-NY into the electron crystallographically refined taxane binding site $^{5,7}$ without steric congestion have not been completely satisfying. Geney et al. ${ }^{18}$ apparently faced the same problem, since they report extensive rearrangement of the protein following docking of PTX-NY onto the DTX ligand-placeholder in unrefined $1 \mathrm{TUB}^{36}$ and subsequent protein-ligand minimization. A risk in the latter procedure is that introducing a pre-determined conformation into the binding cleft followed by minimization in order to relieve short nonbonded contacts can cause the system to deviate significantly from the experimental structure. However, in order to make the fairest possible comparison between PTX-NY and T-Taxol, we decided to employ the experimental structure (1JFF5) in which both ligands are docked and superimposed (Figure 8 ) as previously pictured both by Geney et al. ${ }^{18}$ and our group. ${ }^{17,19}$ In this way, the primary difference between them is emphasized; namely the path taken by the C-1' to C-3' segment of the C-13 side chain. Figure 8a illustrates that the trace of the EC density clearly encompasses the C-1'-C-3' atoms in T-Taxol, while the same atoms in PTX-NY are not centered in ligand density. Difference density maps for PTX-NY (Figure 8b) express this result another way. The green difference contour illustrates density unfilled by the ligand, while the red contour represents density that is incorrectly filled. By contrast, the T-Taxol conformer is in complete agreement with the same maps and in accord with very similar visualizations resulting from analysis of reconstructed PTX-NY (Figure 5). ${ }^{17,19}$

\section{Conclusions and Prospects}

Paclitaxel is one of the unique blockbuster anticancer drugs to emerge from natural product screening in the past two decades. Analogs continue to be created and evaluated in the clinic for improved efficacy, reduced toxicity and the ability to elude resistance. Firm knowledge of the conformation of the molecule bound to its tubulin-microtubule target would answer longstanding questions, while contributing to future efforts to remodel taxanes with the baccatin core or to completely re-engineer the molecule's architecture. Accordingly, we have prepared a series of fluoro and deuterio labeled derivatives of PTX suitable for measurement of interatomic distances by solid state ${ }^{2} \mathrm{H}\left\{{ }^{19} \mathrm{~F}\right\}$ REDOR NMR. Samples of ligand-doped microtubules were subjected to three weeks of spectrometer time in order to measure each of three pairwise distances. The latter were compared to the same quantities for five PTX conformers, each of which has been proposed to be the bioactive form at the tubulin binding pocket.

The outcome definitively eliminates the polar conformer from consideration. The nonpolar conformer is also eliminated by the combination of the present data with our previous REDOR data. ${ }^{15}$ The PTX-NY structure fits the REDOR data well, though there are irregularities in its molecular geometry as illustrated by Figures 6 and 7 and Table 3. The latter alone, however, do not disqualify the conformer from bioactive candidacy. Critical is the observation that the shape of PTX-NY's C-13 side chain is in conflict with the experimental electron crystallographic density. On the other hand, the T-Taxol structure passes three fundamentally important tests. First, this conformation is within $0.7 \AA$ of four well-defined REDOR distances and fully consistent with the fifth. Second, it is the only conformer in Table 2 that is compatible 
with the EC density. Third, it is unique in being a template for synthesis of bridged taxanes that match or surpass both the binding affinity and cytotoxicity characteristics of the paclitaxel parent. For these reasons, the T-Taxol conformation proposed by a combination of structure and modeling techniques ${ }^{7}$ and by synthesis and bioassay ${ }^{20}$ is confirmed by REDOR measurement of interatomic distances.

Finally, with respect to evaluating prospective bioactive taxane conformations at the binding site of $\beta$-tubulin, it must be noted that the electron crystallographic binding model that led to the T-Taxol proposal was derived from $\mathrm{Zn}^{+2}$-stabilized tubulin sheets 5,7 and not genuine microtubules. It is thus necessary to determine whether or not this model is suitable as a guide to the 3D-shape of the bioactive form at the tubulin binding site. ${ }^{33}$ It is no coincidence that virtually every recent synthetic program attempting to prepare more potent and less resistant taxanes based on biostructural principles has employed the EC structure. ${ }^{18,20,29,37}$ Furthermore, the tubulin dimer structure derived from $\mathrm{Zn}^{+2}$-stabilized sheets has been modeled into the $8 \AA$ resolution microtubule structure determined by cryoelectron microscopy 38 and shown to be entirely consistent with the MT structure. Finally, as we have pointed out previously, $17,20,29$ not only is the REDOR geometry derived from lyophilized MTs coincident with the T-Taxol form (Table 2), but bioactivities in situations where MTs are present as soluble dynamic entities can be significantly improved by exploiting the EC structure and bound ligand from stabilized tubulin sheets. The implication is clear. While the details of tubulin polymerization may vary on the level of protein assembly, the taxane binding site sequestered within $\beta$-tubulin appears to be faithfully retained in the two situations. This underscores the necessity that alternative bioactive conformations for paclitaxel pass the three tests outlined in the previous paragraph.

\section{Experimental Section}

\section{Synthesis of labeled paclitaxels}

Full experimental details of the syntheses of compounds $4-5$ are provided as Supporting Data.

\section{$E_{50}$ Determination}

Pure tubulin was obtained from bovine brain and used in polymerization and REDOR experiments. Polymerization activity of paclitaxel and derivatives was evaluated in the following manner. GTP-tubulin $(5 \mu \mathrm{M})$ in a buffer containing $0.1 \mathrm{M}$ PIPES, $1 \mathrm{mM} \mathrm{MgSO}_{4}, 2$ mM EDTA and $0.1 \mathrm{mM} \mathrm{GTP}$ (pH 6.90) was equilibrated to $37^{\circ} \mathrm{C}$ in a quartz cuvette in a Hewlett Packard Model 8453 diode array spectrophotometer and a baseline was recorded. Polymerization was initiated by addition of the compound to be tested in DMSO, and the extent of assembly was measured as the change in apparent absorption at $350 \mathrm{~nm}$. In all the solutions the percentage of DMSO was maintained as $4 \% \mathrm{v} / \mathrm{v}$, to avoid any effect of DMSO on tubulin assembly. A plot of change in apparent absorption at $350 \mathrm{~nm}$ versus the concentration of the compound was fit to a rectuagular hyperbola to obtain the $\mathrm{ED}_{50}$ value.

\section{NMR Samples}

Paclitaxel analogues $4(0.7 \mu$ moles $)$ and $5(0.1 \mu$ moles $)$ were bound $1: 1$ to tubulin to form microtubule complexes following the protocol described earlier ${ }^{14}$ with the following modifications: GMPCPP rather than GTP was employed as the nucleotide, and $20 \mathrm{mM}$ sucrose and $1 \%$ PEG $\left(M_{n} 8,000\right)$ were used as the lyo- and cryoprotectants, respectively. A small amount of the freeze dried material was reconstituted in $10 \mathrm{mM}$ phosphate buffer (pH 7.0) and examined by electron microscopy; normal microtubules were observed. The complexes were packed into rotors under a dry atomosphere. A reference sample for testing ${ }^{2} \mathrm{H}\left\{{ }^{19} \mathrm{~F}\right\}$ REDOR dephasing was prepared by dissolving D-[2- $\left.{ }^{2} \mathrm{H}, 3-{ }^{19} \mathrm{~F}\right]$ alanine $(10 \mathrm{mg})$ with HEPES buffer (100 $\mathrm{mg}$ ), flash freezing the solution, and then lyophilizing at low temperature. A control sample 
that contained no ${ }^{19} \mathrm{~F}$ was prepared by physically mixing $5 \mathrm{mg}$ of $\mathrm{D}-\left[3-{ }^{2} \mathrm{H}_{3}\right]$ alanine $(5 \mathrm{mg})$ with sulfur powder $(100 \mathrm{mg})$. This mixture was used to confirm that a null REDOR difference signal was observed (Figure $\mathrm{S} 3$ of the Supplementary Material) from a $32-\mathrm{T}_{\mathrm{r}}{ }^{2} \mathrm{H}\left\{{ }^{19} \mathrm{~F}\right\}$ REDOR experiment after 1 million scans.

\section{Spectrometer}

Deuterium NMR spectra were obtained using a spectrometer equipped with a four-frequency (HFCD) transmission-line probe operating at a ${ }^{1} \mathrm{H}$ frequency of $500.5 \mathrm{MHz}$ and a ${ }^{2} \mathrm{H}$ frequency of $76.83 \mathrm{MHz}$. Tune and match circuits for each frequency were external to the magnet. The probe had a 12-mm long, 6-mm inside-diameter analytical coil and a Chemagnetics/Varian magic-angle spinning ceramic stator. Five-mm thin-wall ceramic rotors were spun at $8000 \mathrm{~Hz}$ with the speed under active control to within $\pm 2 \mathrm{~Hz}$. A 12-T static magnetic field was provided by an $89-\mathrm{mm}$ bore Magnex superconducting solenoid. The spectrometer was controlled by a Tecmag Apollo pulse programmer. Levels of all radiofrequency pulses were under active control during data acquisition by sampling of test pulses fired on each channel in use immediately after each scan. ${ }^{27}$

\section{REDOR}

The version of REDOR used in these experiments (Figure S1) had a single ${ }^{2} \mathrm{H} 180^{\circ}$ pulse (5.6 $\mu \mathrm{s})$ and $16 \mathrm{n}(\mathrm{n}=2,3, \ldots){ }^{19} \mathrm{~F} 180^{\circ}$ pulses $(5.8 \mu \mathrm{s})$. The phases of the ${ }^{19} \mathrm{~F}$ pulses followed the $\mathrm{xy} 8$ phase-alternation scheme. ${ }^{39}$ This combination gave the best echo refocusing and most complete dephasing (Figure S2). Internuclear distances were calculated from the REDOR dephasing by spectral simulations performed using SIMPSON. ${ }^{40}$ The ${ }^{1} \mathrm{H} \rightarrow{ }^{2} \mathrm{H}$ matched crosspolarization transfer was at $54 \mathrm{kHz}$ for $3 \mathrm{~ms}$, with a ${ }^{1} \mathrm{H} 90^{\circ}$ pulse of $2.5 \mu$ s and $100-\mathrm{kHz}$ dipolar decoupling with TPPM $^{41}$ phase modulation.

\section{Acknowledgement}

The work at Virginia Polytechnic Institute and State University, SUNY Binghamton, and Emory University was supported by the NIH grant CA-69571, and the work at Washington University was supported by NIH grant EB-001964; we are grateful for this support. We thank William Bebout (VPISU) for mass spectroscopic determinations, and Andrew Norris and Peggy Brodie (VPISU) for A2780 cytotoxicity assays. We are likewise grateful to Professor Iwao Ojima for providing the CVFF coordinates to PTX-NY.

\section{References and Notes}

1. a Rowinsky EK. Ann. Rev. Med 1997;48:353-374. [PubMed: 9046968] b Crown J, O'Leary M. The Lancet 2000;355:1176-1178. b Crown J, O'Leary M, Ooi W-S. The Oncologist 2004;9(Suppl 2):2432. [PubMed: 15161988] c Mekhail T, Markman M. Expert Opin. Pharmacother 2002;3:755-766. [PubMed: 12036415]

2. Kingston, DGI. Anticancer Agents from Natural Products. Cragg, GM.; Kingston, DGI.; Newman, DJ., editors. CRC Press; Boca Raton, FL: 2005. p. 89-122. b Geney R, Chen J, Ojima I. Med. Chem 2005;1:125-139. [PubMed: 16787308] c Fang W-S, Liang X-T. Mini-Rev. Med. Chem 2005;5:1-12. [PubMed: 15638787] d Zefirova ON, Nurieva EV, Ryzhov AN, Zyk NV, Zefirov NS. Russ. J. Org. Chem 2005;41:315-351.

3. a Schiff PB, Fant J, Horwitz SB. Nature 1979;277:665-667. [PubMed: 423966] b Wilson L, Jordan MA. Nat. Rev. Cancer 2004;4:253-265. [PubMed: 15057285] c Horwitz SB. Trends Pharmacol. Sci 1992;13:134-136. [PubMed: 1350385] d Jordan MA, Toso RJ, Thrower D, Wilson L. Proc. Natl. Acad. Sci. U.S.A 1993;90:9552-9556. [PubMed: 8105478] e Blagosklonny MV, Fojo T. Int. J. Cancer 1999;83:151-156. [PubMed: 10471519]

4. Blagosklonny MV, Giannakakou P, El-Deiry WS, Kingston DGI, Higgs PI, Neckers L, Fojo T. Cancer Res 1997;57:130-135. [PubMed: 8988053]

5. Lowe J, Li H, Downing KH, Nogales E. J. Mol. Biol 2001;313:1045-1057. [PubMed: 11700061] 
6. Sánchez-Pedregal VM, Reese M, Meiler J, Blommers MJJ, Griesinger C, Carlomagno T. Angew. Chem. Int. Ed 2005;44:4172-4175.

7. Snyder JP, Nettles JH, Cornett B, Downing KH, Nogales E. Proc. Natl. Acad. Sci. U.S.A 2001;98:5312-5316. [PubMed: 11309480]

8. a Dubois J, Guenard D, Gueritte-Voeglein F, Guedira N, Potier P, Gillet B, Betoeil J-C. Tetrahedron 1993;49:6533-6544. b Williams HJ, Scott AI, Dieden RA, Swindell CS, Chirlian LE, Francl MM, Heerding JM, Krauss NE. Can. J. Chem 1994;72:252-260. c Cachau RE, Gussio R, Beutler JA, Chmurny GN, Hilton BD, Muschik GM, Erickson JW. Supercomput. Appl. High Perform. Comput 1994;8:24-34.

9. Vander Velde DG, Georg GI, Grunewald GL, Gunn CW, Mitscher LA. J. Am. Chem. Soc 1993;115:11650-11651.

10. Paloma LG, Guy RK, Wrasidlo W, Nicolaou KC. Chem. Biol 1994;1:107-112. [PubMed: 9383378]

11. Ojima I, Chakravarty S, Inoue T, Lin S, He L, Horwitz SB, Kuduk SC, Danishefsky SJ. Proc. Natl. Acad. Sci. U.S.A. 1999;96:4256-4261. [PubMed: 10200249]

12. Ojima I, Kuduk SD, Chakravarty S, Ourevitch M, Begue J-P. J. Am. Chem. Soc 1997;119:55195527.

13. Snyder JP, Nevins N, Cicero DO, Jansen J. J. Am. Chem. Soc 2000;122:724-725.

14. Gullion T, Schaefer J. Adv. Magn. Reson 1989;13:58-82.

15. Li Y, Poliks B, Cegelski L, Poliks M, Gryczynski Z, Piszczek G, Jagtap PG, Studelska DR, Kingston DGI, Schaefer J, Bane S. Biochemistry 2000;39:281-291. [PubMed: 10630987]

16. Ojima I, Inoue T, Chakravarty S. J. Fluorine Chem 1999;97:3-10.A related study, which has not yet been reported in full, used the radio frequency driven dipolar recoupling (RFDR) technique. This work indicated a distance of $6.5 \AA$ between the fluorines of 2-( $p$-fluorobenzoyl)-3'-( $p$ fluorophenyl)-10-acetyldocetaxel (3), but it is not clear that this result is directly comparable to the REDOR results reported here

17. Alcaraz AA, Mehta AK, Johnson SA, Snyder JP. J. Med. Chem 2006;49:2478-2488. [PubMed: 16610791]

18. Geney R, Sun L, Pera P, Bernacki RJ, Xia S, Horwitz SB, Simmerling CL, Ojima I. Chem. Biol 2005;12:339-348. [PubMed: 15797218]

19. Johnson SA, Alcaraz A, Snyder JP. Org. Lett 2005;7:5549-5552. [PubMed: 16320988]

20. Ganesh T, Guza C, Bane S, Ravindra R, Shanker N, Lakdawala AS, Snyder JP, Kingston DGI. Proc. Natl. Acad. Sci. U.S.A 2004;101:10006-10011. [PubMed: 15226503]

21. Ojima I, Lin S, Inoue T, Miller ML, Borella CP, Geng X, Walsh JJ. J. Am. Chem. Soc 2000;122:53435353.

22. Chen S-H, Kadow JF, Farina V, Fairchild CR, Johnston KA. J. Org. Chem 1994;59:6156-6158.

23. Holton RA, Zhang Z, Clarke PA, H. N, Procter DJ. Tetrahedron Lett 1998;39:2883-2886.

24. Brieva R, Crich JZ, Sih CJ. J. Org. Chem 1993;58:1068-1075.

25. Kingston DGI, et al. J. Med . Chem 1998;41:3715-3726. [PubMed: 9733497]

26. A reviewer asked whether there is any non-specific binding of the paclitaxel analogs to tubulin. We do not believe that there is any significant non-specific binding in these samples. The molar ratio of the ligand:tubulin dimer was $1: 1$, and the $\mathrm{K}_{\mathrm{d}}$ for paclitaxel binding to microtubules is about $15 \mathrm{nM}$. Even if the affinities of the REDOR probes for the paclitaxel site on tubulin were 100-fold less than the affinity of paclitaxel for microtubules, $>95 \%$ of the probe would be bound to the protein under the conditions used to create the samples. Since the REDOR probes are nearly as active as paclitaxel as promoters of tubulin assembly, and since the structural perturbation between paclitaxel and the analogs is very small, it is reasonable to assume that the spectra are obtained on a homogeneous, fully bound sample

27. Stueber D, Mehta AK, Chen Z, Wooley KL, Schaefer J. J. Polym. Sci. B: Polym. Phys 2006;44:27602775.

28. Schaefer, J.; McKay, RA. U.S. Patent 5,861,748. 1999.

29. Kingston DGI, Bane S, Snyder JP. Cell Cycle 2005;4(2):279-289. [PubMed: 15611640]

30. Boge TC, Wu Z-J, Himes RH, Vander Velde DG, Georg GI. Bioorg. Med. Chem. Lett 1999;9:30473052. [PubMed: 10571173] 
31. a Ojima I, Geng X, Miller ML, Lin S, Pera P, Bernacki RJ. Bioorg. Med. Chem. Lett 2002;12:349352. [PubMed: 11814794] b Geng X, Miller ML, Lin S, Ojima I. Org. Lett 2003;5:3733-3736. [PubMed: 14507217] b Querolle O, Dubois J, Thoret S, Dupont C, Guéritte F, Guénard D. Eur. J. Org. Chem 2003:542-550. c Querolle O, Dubois J, Thoret S, Roussi F, Montiel-Smith S, Gueritte F, Guénard D. J. Med. Chem 2003;46:3623-3630. [PubMed: 12904066]

32. Atomic coordinates of the computationally refined T-Taxol-tubulin structure can be found in the Supporting Information of Ref. 17

33. We thank a referee for suggesting that we add this section

34. Mastropaolo D, Camerman A, Luo Y, Brayer GD, Camerman N. Proc. Natl. Acad. Sci. USA 1995;92:6920-6924. [PubMed: 7624344]

35. Guéritte-Voegelein F, Guénard D, Mangatal L, Potier P, Guilhem J, Césario M, Pascard C. Acta Crystallogr. C 1990;46:781-784.

36. Nogales E, Wolf SG, Downing KH. Nature 1998;391:199-203. [PubMed: 9428769]

37. a Boge TC, Wu Z-J, Himes RH, Vander Velde DG, Georg GI. Bioorg. \& Med. Chem. Lett 1999;9:3047-3052. [PubMed: 10571173] b He L, Jagtap PG, Kingston DGI, Shen H-J, Orr GA, Horwitz SB. Biochemistry 2000;39:3972-3978. [PubMed: 10747785] c Giannakakou P, Gussio R, Nogales E, Downing KH, Zaharevitz D, Bollbuck B, Poy G, Sackett D, Nicolaou KC, Fojo T. Proc. Nat. Acad. Sci. USA 2000;97:2904-2909. [PubMed: 10688884] d Barboni L, Lambertucci C, Appendino G, Vander Velde DG, Himes RH, Bombardelli E, Wang M, Snyder JP. J. Med. Chem 2001;44:1576-1587. [PubMed: 11334567] e Querolle O, Dubois J, Thoret S, Roussi F, Guéritte F, Guénard D. J. Med. Chem 2004;47:5937-5944. [PubMed: 15537348] f Hari M, Loganzo F, Annable T, Tan X, Musto S, Morilla DB, Nettles JH, Snyder JP, Greenberger' LM. Mol. Can. Ther 2006;5:270278.

38. a Nogales E, Whittaker M, Milligan RA, Downing KH. Cell 1999;96:79-88. [PubMed: 9989499] b Li H, DeRosier DJ, Nicholson WV, Nogales E, Downing KH. Structure 2002;10:1317-1328. [PubMed: 12377118]

39. Gullion T, Baker DB, Conradi MS. J. Magn. Reson 1990;89:479-484.

40. Bak M, Rasmussen JT, Nielsen NC. J. Magn. Reson 2000;147:296-330. [PubMed: 11097821]

41. Bennett AE, Rienstra CM, Auger M, Lakshmi KV, Griffin RG. J. Chem. Phys 1995;103:6951-6958.

\section{Supplementary Material}

Refer to Web version on PubMed Central for supplementary material. 


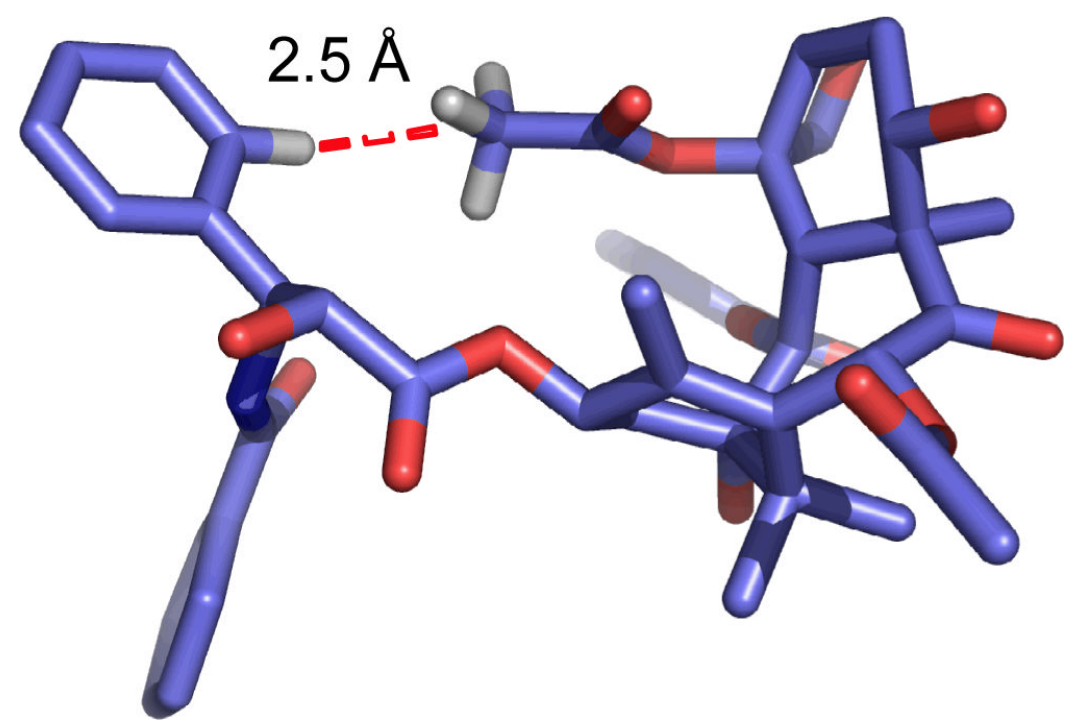

Figure 1.

The T-Taxol conformation illustrating the short $\mathrm{C}-\mathrm{H}$ distance between the centroid of the $\mathrm{C} 4$ acetate group and the meta-hydrogen of the C3' phenyl moiety. 
Paik et al.

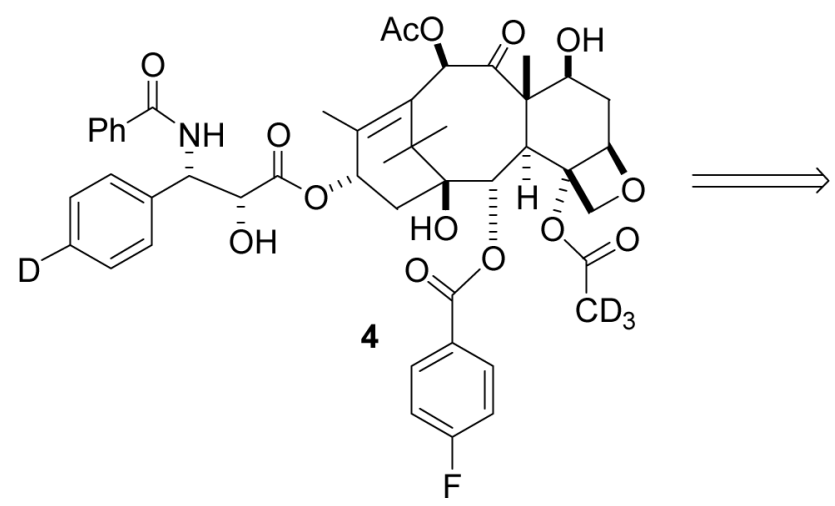

Page 14

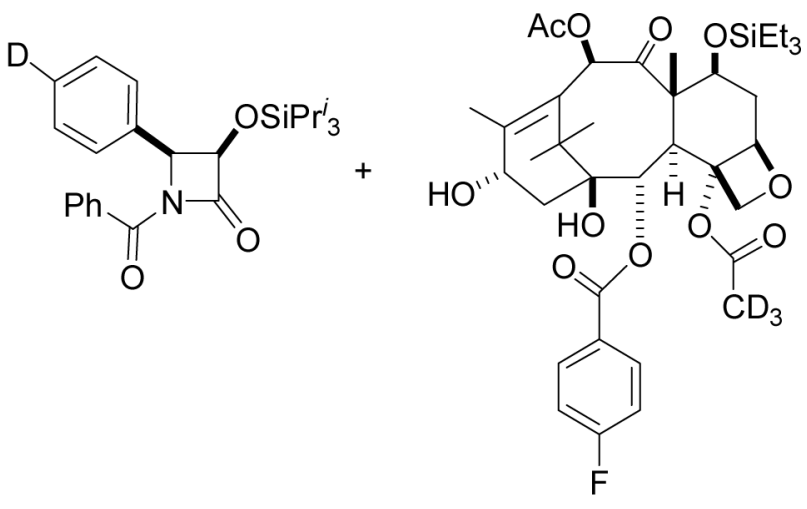

Scheme 1.

Retrosynthesis of Ligand 4 


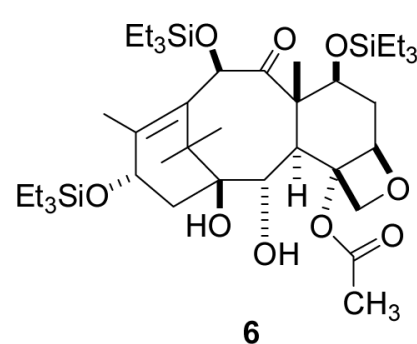

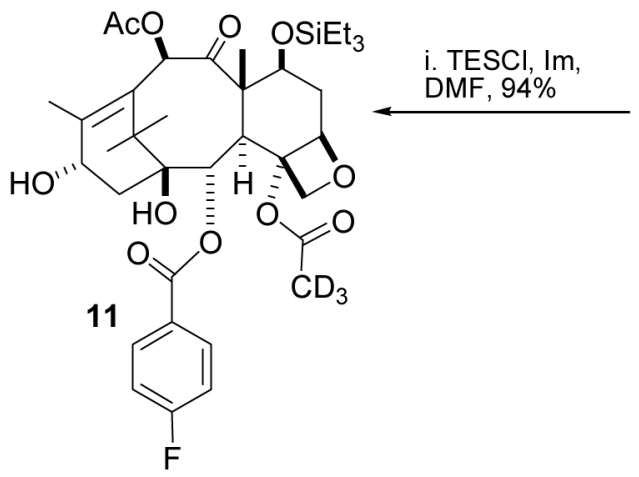

Scheme 2.

Synthesis of Labeled Baccatin 11
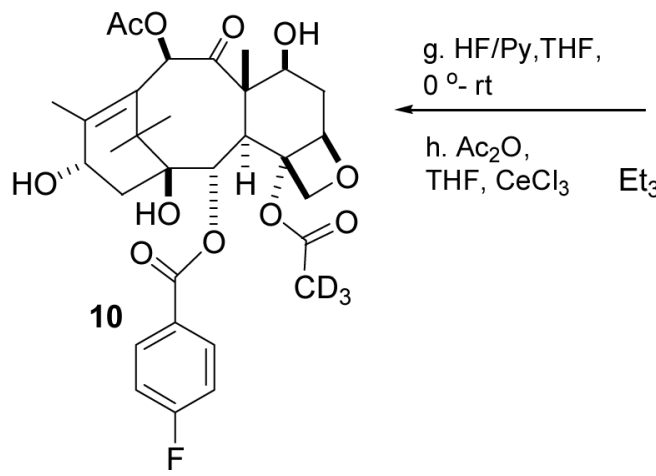
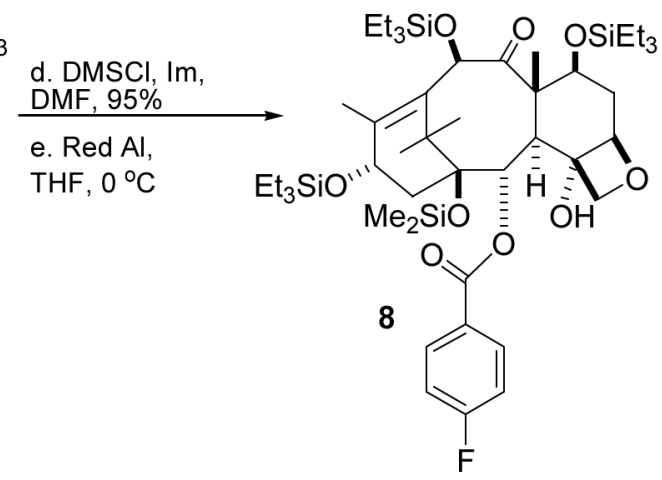

f. LHMDS, $\mathrm{THF}, 0^{\circ} \mathrm{C}$ $\mathrm{CD}_{3} \mathrm{COCl}$

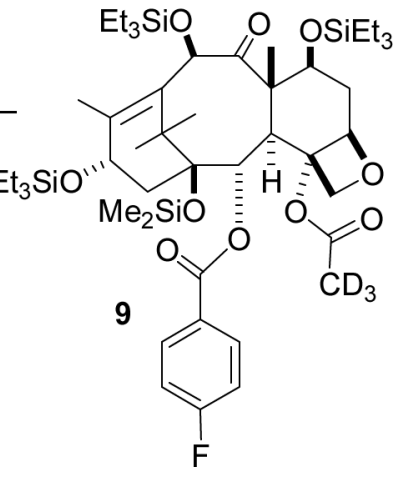


<smiles>O=Cc1ccc(Br)cc1</smiles>

a. $\mathrm{HOCH}_{2} \mathrm{CH}_{2} \mathrm{OH}$, cat. TsOH $\mathrm{PhCH}_{3}$, reflux

b. sec-BuLi, THF, $-78^{\circ} \mathrm{C}$ quench $\mathrm{D}_{2} \mathrm{O}, 79 \%$ overall

12<smiles>[2H]c1ccc(C2OCCO2)cc1</smiles>

13 a. Acetone/ $\mathrm{H}_{2} \mathrm{O}$, cat. $\mathrm{TsOH}$

b. $p$-anisidine, $\mathrm{MgSO}_{4}, \mathrm{CH}_{2} \mathrm{Cl}_{2} \mathrm{~A}$

c. $\mathrm{AcOCH}_{2} \mathrm{COCl}, \mathrm{Et}_{3} \mathrm{~N}$ $\mathrm{CH}_{2} \mathrm{Cl}_{2},-78^{\circ} \mathrm{C}$ to rt $72 \%$ overall<smiles>[2H]c1ccc([C@H]2[C@H](OC(C)=O)C(=O)N2[Y6]#N)cc1</smiles>

Lipase Amano, $\mathrm{pH}$ 7.2 phosphate buffer, $\mathrm{CH}_{3} \mathrm{CN}, 92 \%$
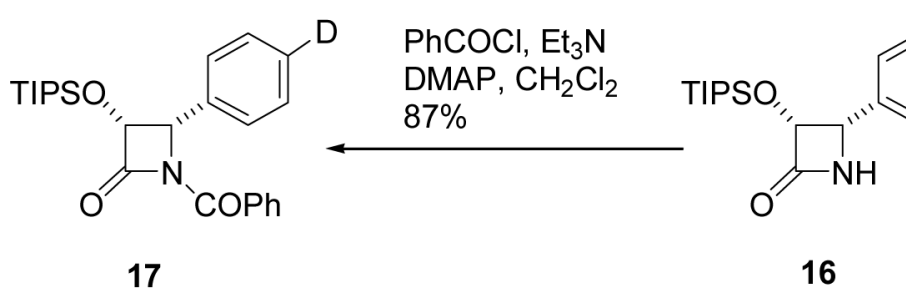
a. $1 \mathrm{M} \mathrm{KOH}, \mathrm{THF}$ b. TIPSCI, Imidazole, DMF
c. $\mathrm{Ce}(\mathrm{IV}), \mathrm{CH}_{3} \mathrm{CN} / \mathrm{H}_{2} \mathrm{O}$, $70 \%$ overall<smiles>[2H]c1ccc([C@H]2[C@H](OC(C)=O)C(=O)N2[PbH])cc1</smiles>

Scheme 3.

Synthesis of $\beta$-lactam 17 


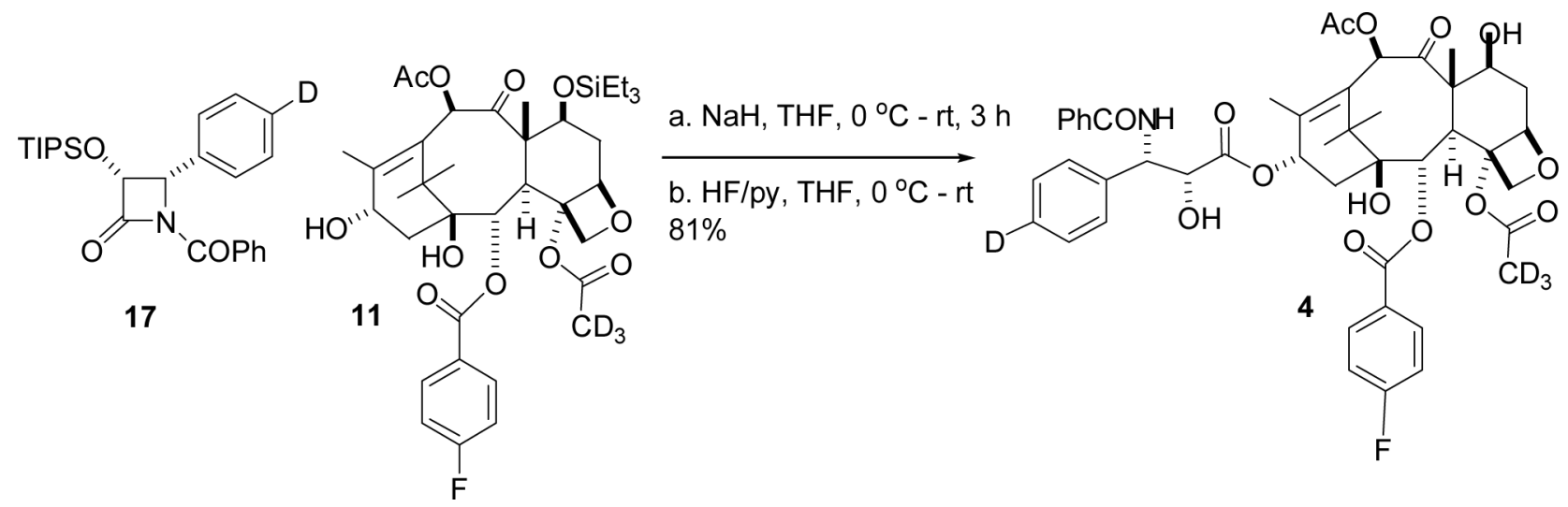

Scheme 4.

Synthesis of Labeled PTX Derivative 4 

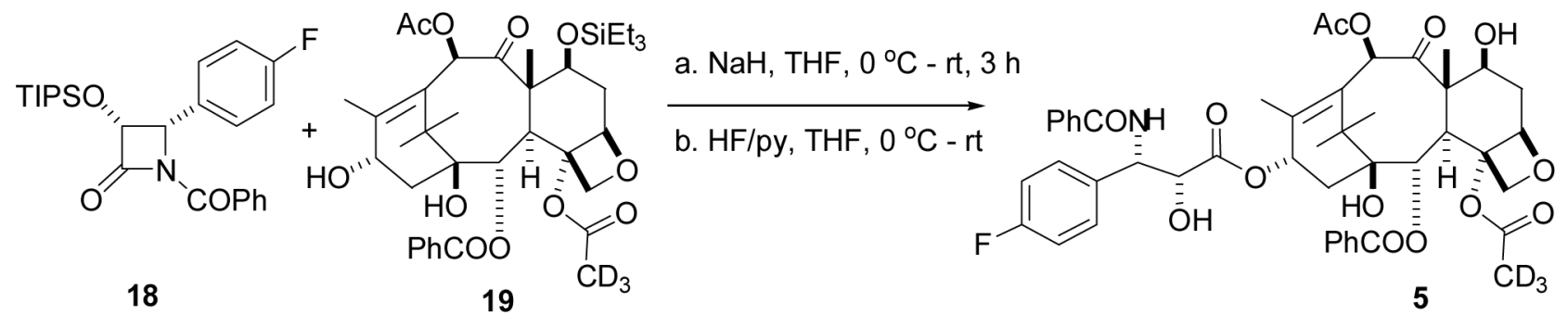

Scheme 5.

Synthesis of Labeled PTX Derivative 5 


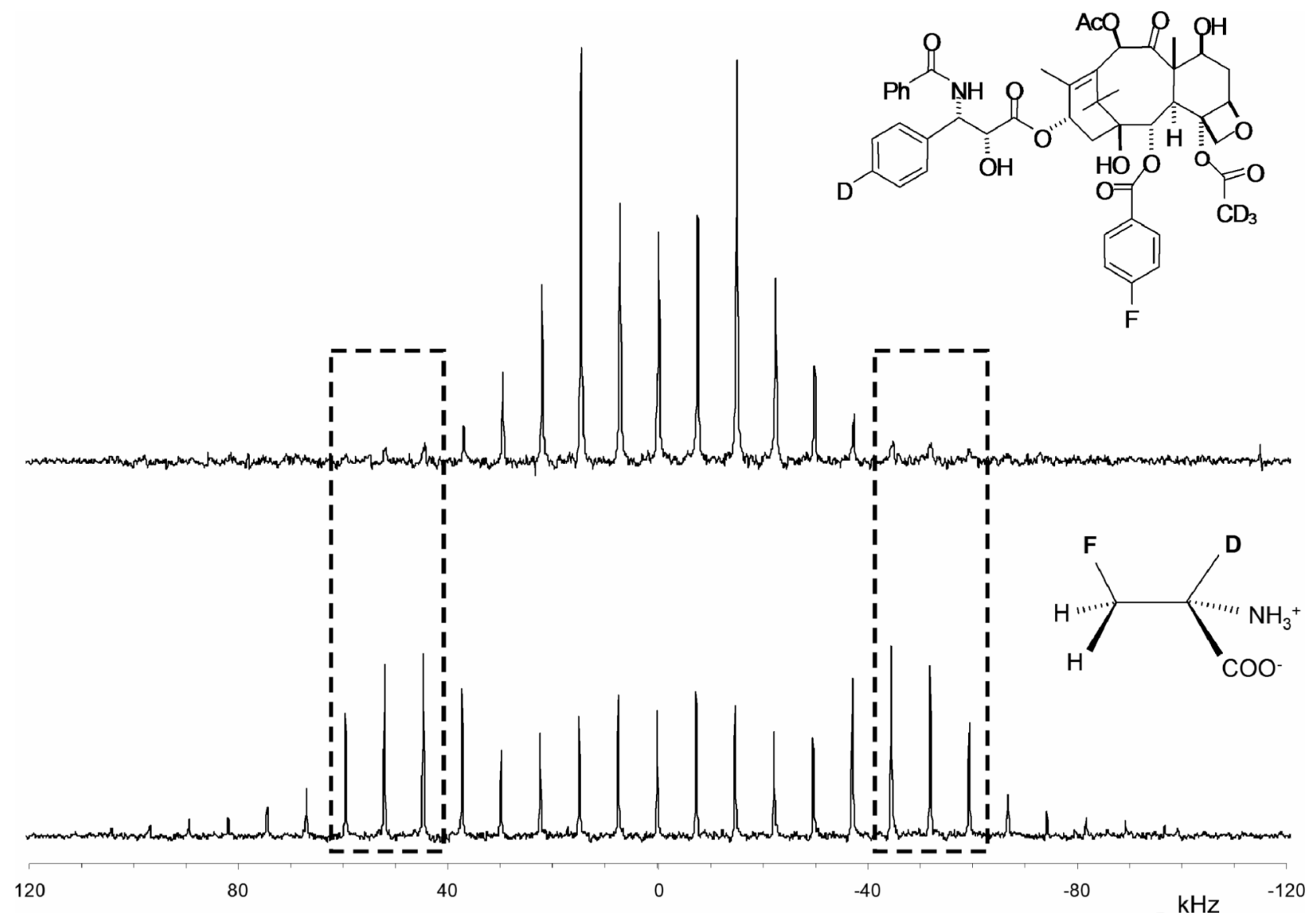

Figure 2.

Cross-polarization magic-angle spinning ${ }^{2} \mathrm{H}$ NMR 2-T $\mathrm{T}$ Hahn-echo spectra of tubulin-bound paclitaxel analog 4 (top) and D-[2- $\left.{ }^{2} \mathrm{H}, 3-{ }^{19} \mathrm{~F}\right]$ alanine dispersed in a solid buffer (bottom). The aromatic ${ }^{2} \mathrm{H}$ spinning sidebands of the paclitaxel analog are much weaker than the sidebands of the deuterated alanine (dotted boxes). 


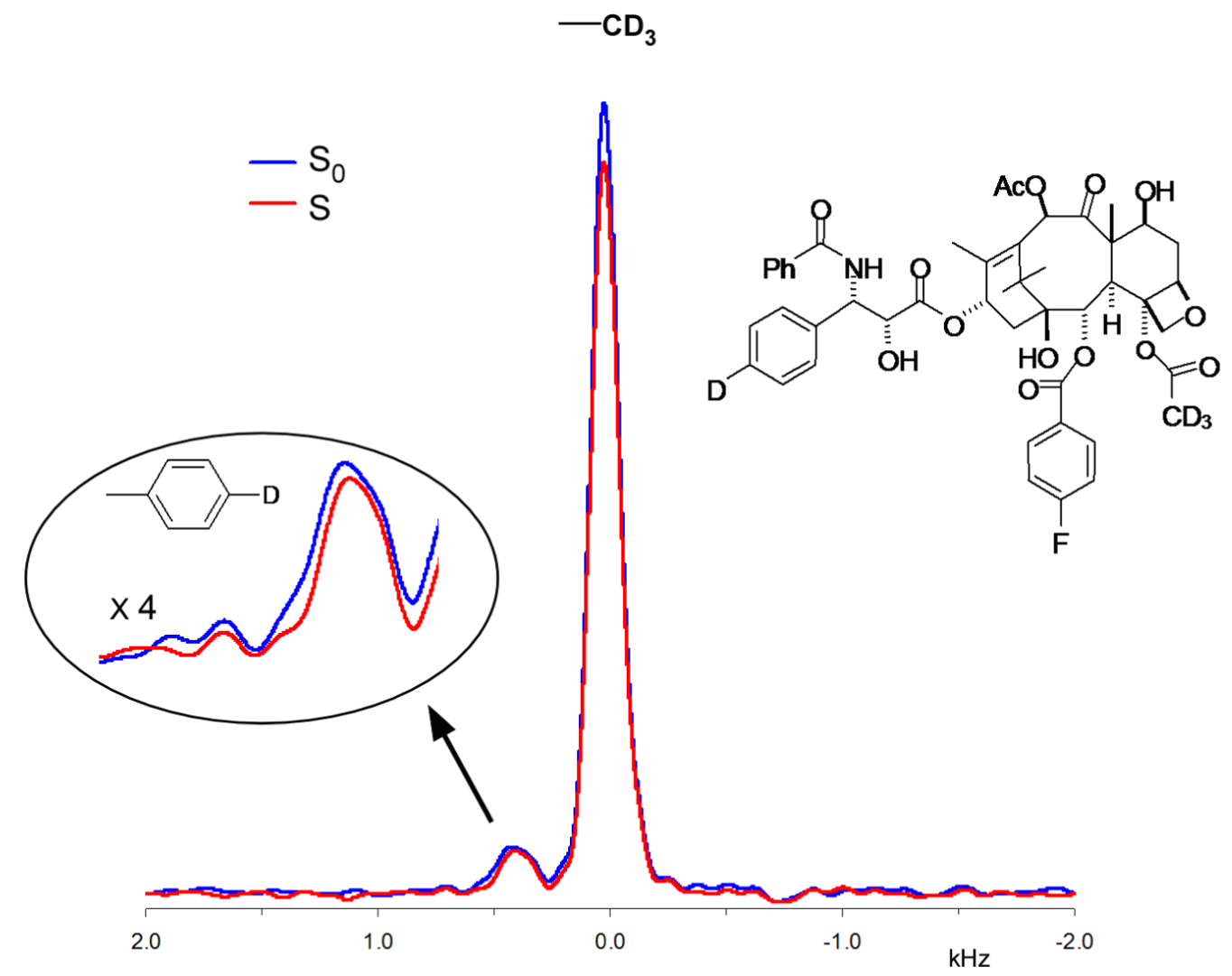

Figure 3.

${ }^{2} \mathrm{H}\left\{{ }^{19} \mathrm{~F}\right\}$ REDOR spectra of tubulin-bound paclitaxel analog 4 after 64 rotor cycles of dipolar evolution with magic-angle spinning at $8 \mathrm{kHz}$. The full-echo spectrum is shown in black and the dephased spectrum in red. The time-domain signals were detected synchronously with the rotor so that all sidebands have been folded into the centerbands. The $\mathrm{CD}_{3}$ peak is assigned zero frequency; the aromatic-D peak appears about $5 \mathrm{ppm}$ to low field. The spectra resulted from the accumulation of 640,000 scans. 


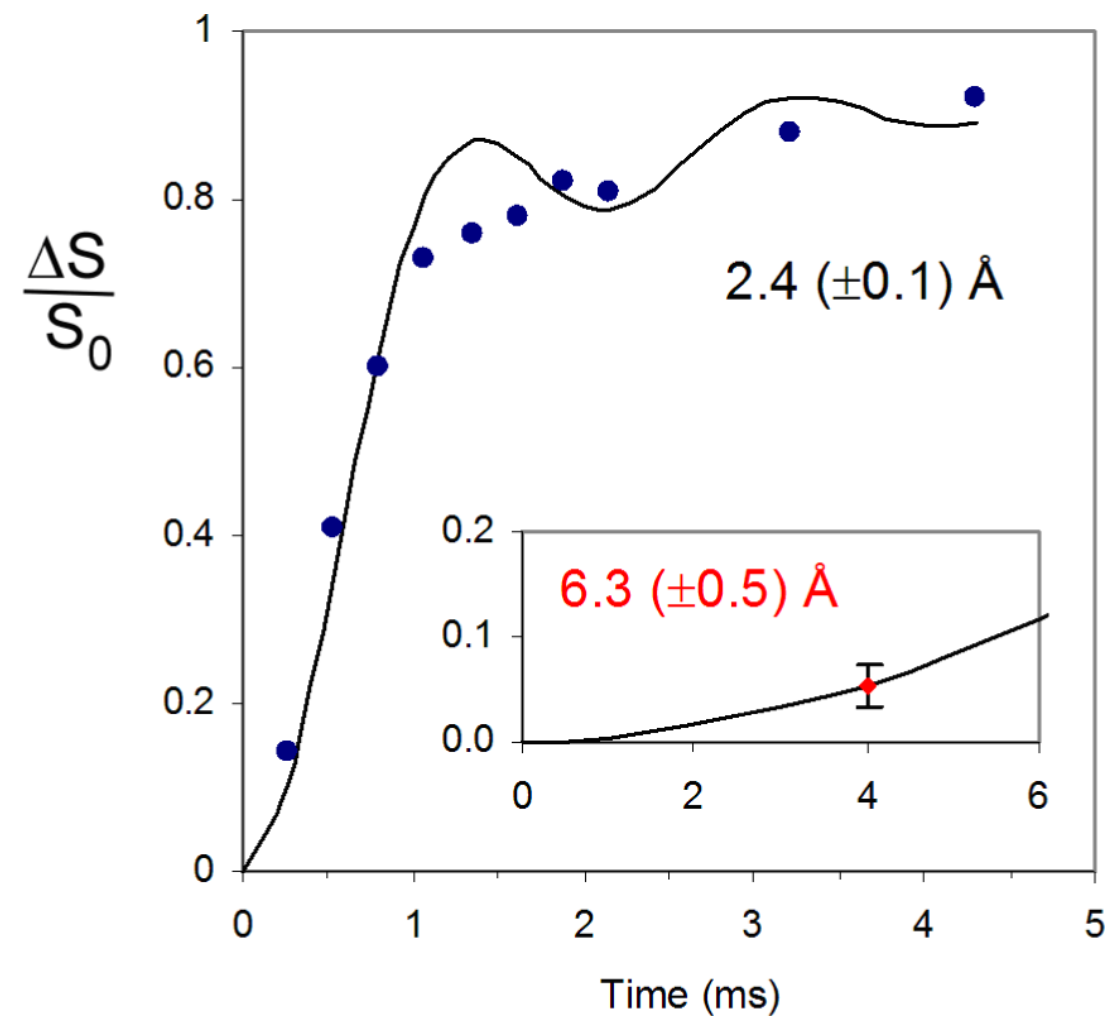

Figure 4.

${ }^{2} \mathrm{H}\left\{{ }^{19} \mathrm{~F}\right\}$ REDOR dephasing $\left(\Delta \mathrm{S} / \mathrm{S}_{0}\right)$ for the alanine sample of Figure 2 . The experimental dephasing (solid black circles) is consistent with that calculated using SIMPSON (solid black line) assuming a single ${ }^{2} \mathrm{H}_{-}{ }^{19} \mathrm{~F}$ distance of $2.4 \AA$. The corresponding REDOR spectra are shown in the Supplemental Material (Figure S2). The inset shows the REDOR dephasing (red) for tubulin-bound paclitaxel analog $\mathbf{5}$ after 32 rotor cycles of dipolar evolution with magic-angle spinning at $8 \mathrm{kHz}$. The REDOR spectra are shown in the Supplemental Material (Figure S3). These spectra resulted from the accumulation of 1,056,000 scans. The experimental dephasing is consistent with that calculated using SIMPSON (solid black line) assuming a single ${ }^{2} \mathrm{H}_{3^{-}}{ }^{19} \mathrm{~F}$ distance of $6.3 \AA$ and the ${ }^{19} \mathrm{~F}$ chemical-shift and ${ }^{2} \mathrm{H}$ quadrupolar tensor parameters of Figure $\mathrm{S} 4$ of the Supplemental Material. The minor effects of $\mathrm{C}_{3}$ motional averaging were ignored. 

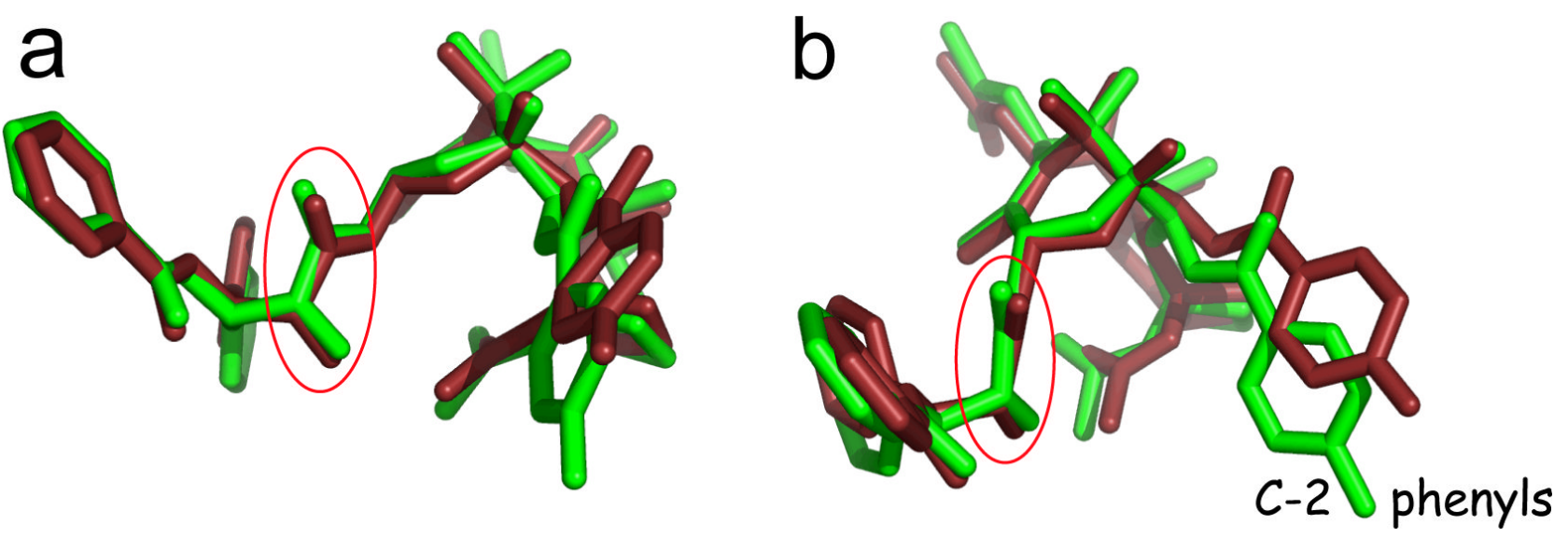

Figure 5.

PTX-NY (green, Ref. 18) T-Taxol (rust, Ref. 7) modified in four torsions of the C-13 side chain as specified in Fig. 5/Ref. 18) two different views (a and b). The key oxygens at C-1' and C-2' are circled. 

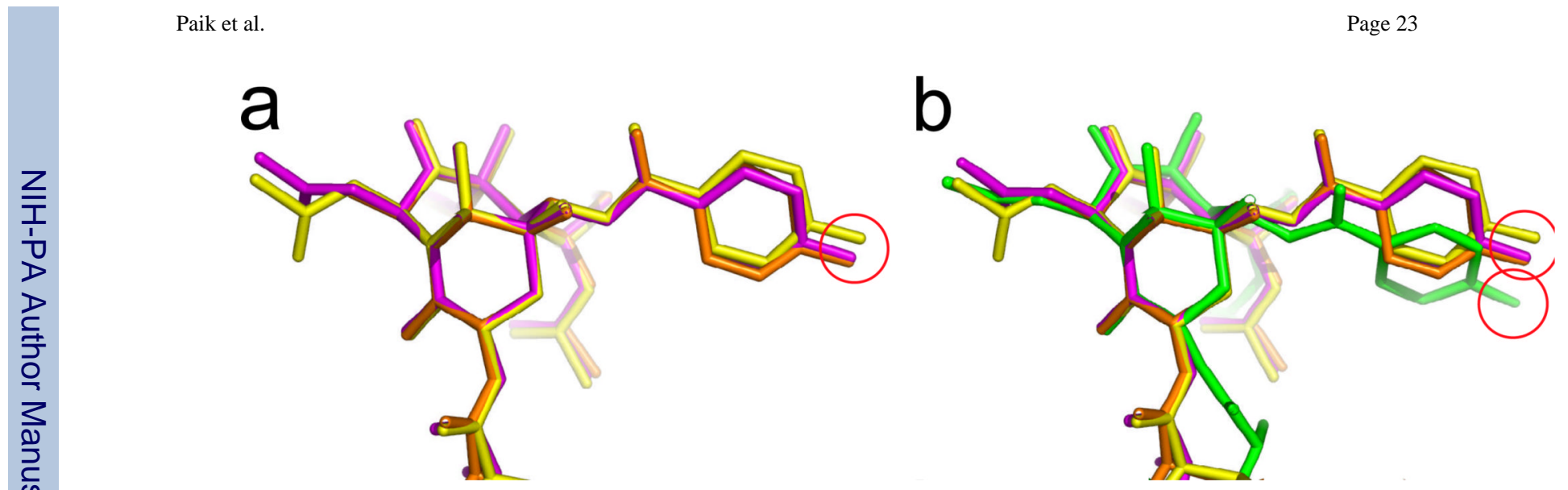

Figure 6.

Taxane superpositions within the baccatin core. a) paclitaxel (magenta), docetaxel (orange), T-Taxol (yellow); b) as in (a) with PTX-NY in green. The C-13 side chain has been truncated at C-2' to emphahsize differences in the remainder of the molecule." 

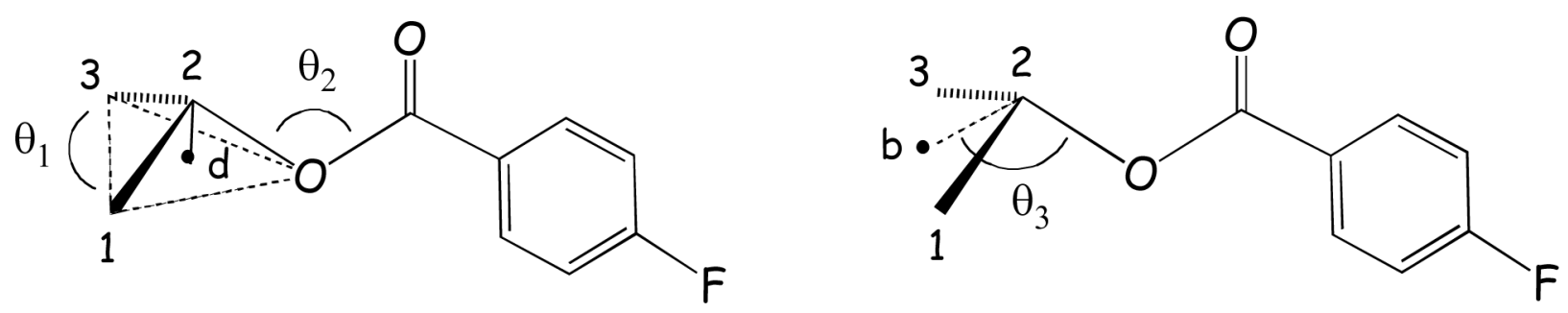

Figure 7.

The geometry around C-2 in the paclitaxel baccatin core: bond angles $\theta_{1}$ (C1-C2-C3), $\theta_{2}$ (C2$\mathrm{O}-\mathrm{C}(=\mathrm{O})$ ) and $\theta_{3}$. The latter measures from the bisector (b) of C-1 and C-3 to the ester $\mathrm{O}$ (i.e. (b-C2-O)). Variable d corresponds to the distance from C-2 to the centroid of C-1, C-3 and O. 

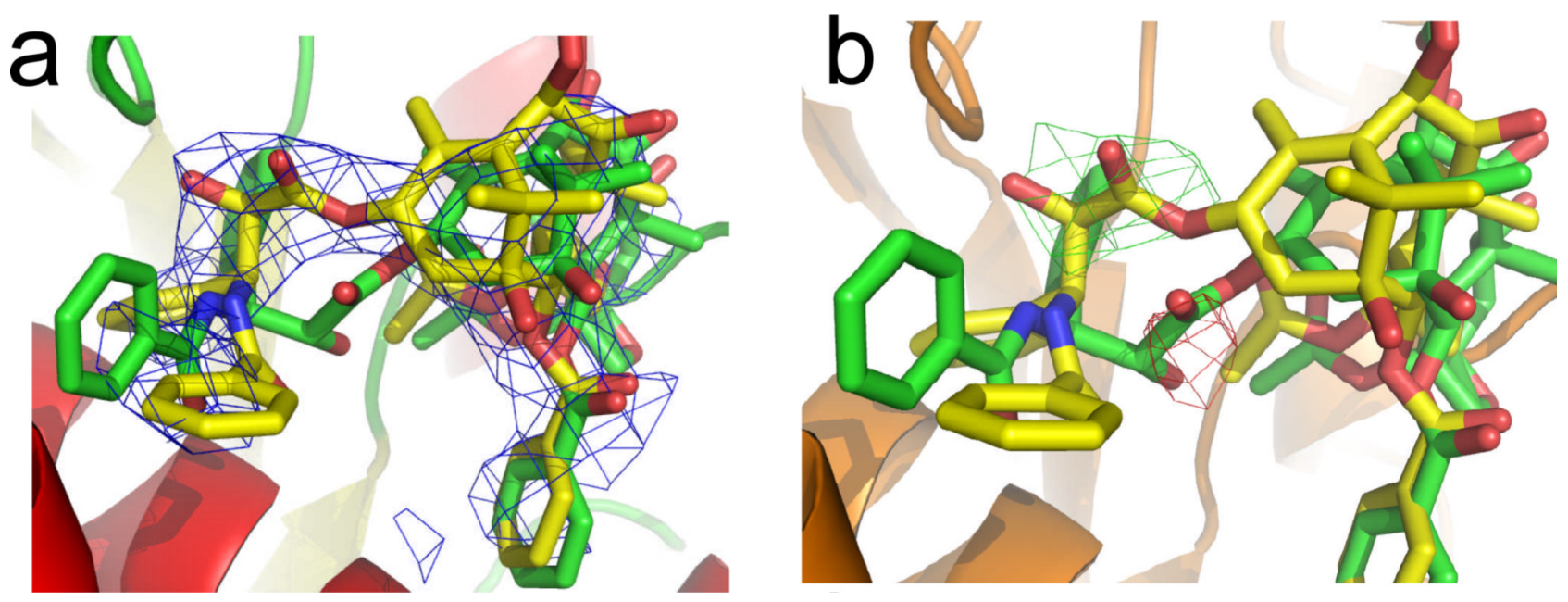

Figure 8.

The structures of T-Taxol (yellow) and PTX-NY ${ }^{18}$ (green) superposed in the 1JFF tubulin binding site. a) The $2 \mathrm{~F}_{\text {obs }}-\mathrm{F}_{\text {calc }}$ omit map is shown as a blue $3 \mathrm{D}$ contour; b) Difference maps $\left(\mathrm{F}_{\text {obs }}-\mathrm{F}_{\text {calc }}\right)$ for the PTX-NY structure. Green corresponds to unfilled density, red to incorrectly filled density. 
Table 1

Bioactivity of paclitaxel and analogs

\begin{tabular}{ccc}
\hline Compound & Tubulin Assembly activity, $\mathbf{E D}_{\mathbf{5 0}}, \boldsymbol{\mu M}$ & $\mathbf{A 2 7 8 0}_{\mathbf{M}}$ Cytotoxicity $\mathbf{I C}_{\mathbf{5 0}}, \boldsymbol{\mu M}$ \\
\hline $\mathbf{1}(\mathrm{PTX})$ & $1.7 \pm 0.4$ & 0.023 \\
$\mathbf{4}$ & $3.5 \pm 0.7$ & 7.6 \\
$\mathbf{5}$ & $2.6 \pm 0.5$ & 0.047 \\
\hline
\end{tabular}




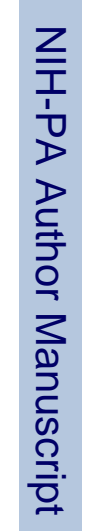

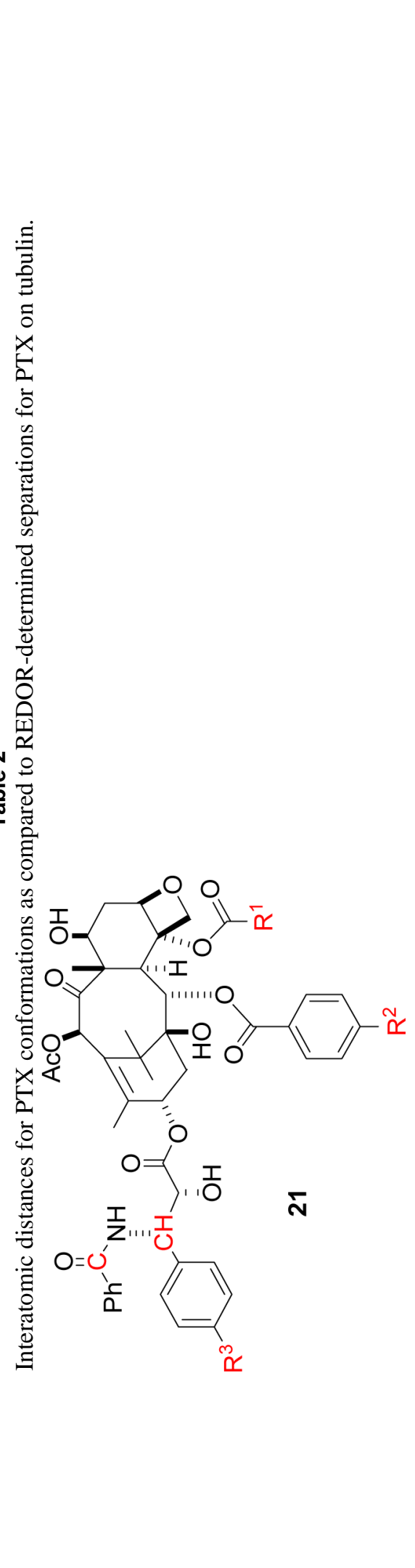

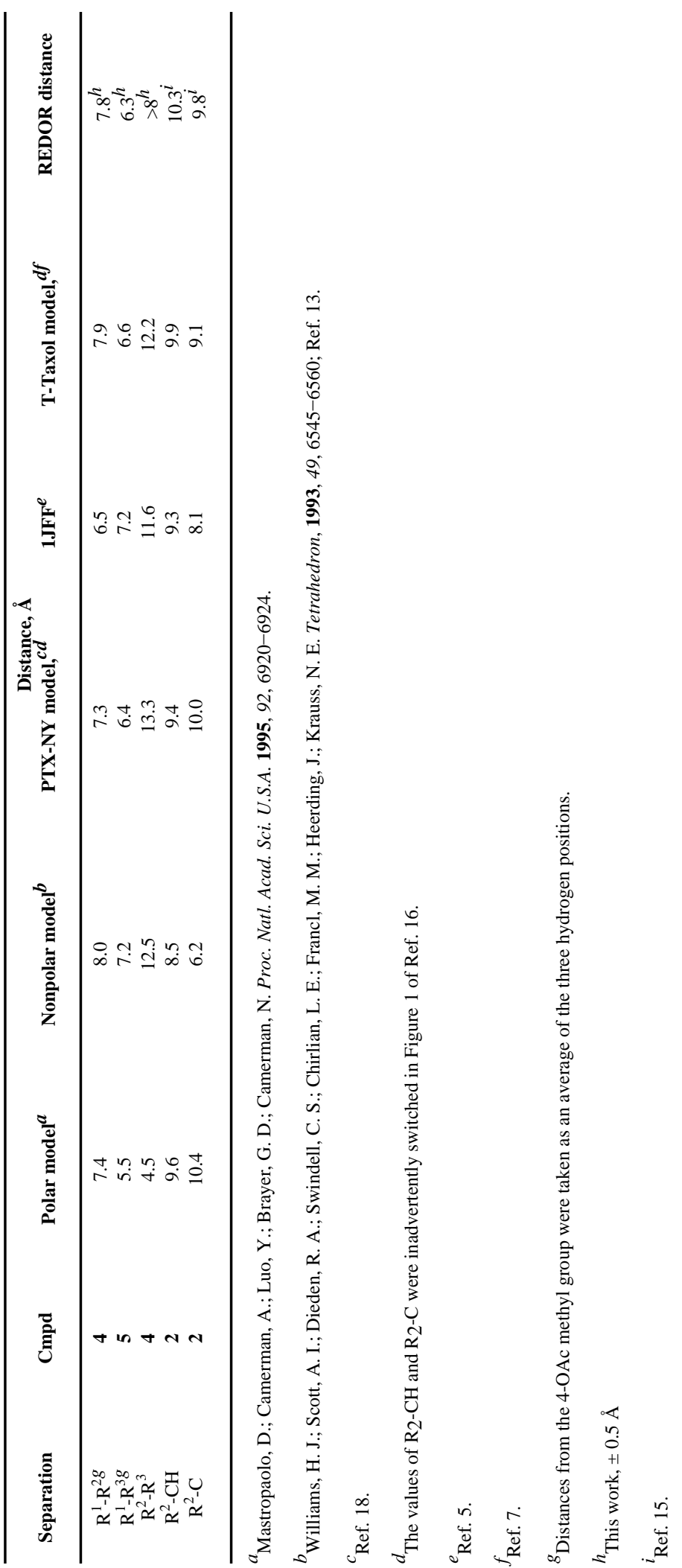


Table 3

Geometry around C-2 for selected taxanes as defined in Figure 7; degrees and $\AA$.

\begin{tabular}{|c|c|c|c|c|}
\hline & $\theta_{1}$ & $\theta_{2}$ & $\boldsymbol{\theta}_{3}$ & d \\
\hline PTX X-ray & 117.4 & 119.6 & 123.5 & 0.49 \\
\hline DTX X-ray & 117.3 & 119.6 & 121.7 & 0.50 \\
\hline T-Taxol & 119.1 & 119.1 & 123.9 & 0.48 \\
\hline PTX-NY & 125.3 & 123.1 & 130.6 & 0.41 \\
\hline
\end{tabular}

